\title{
Recent advances in liver transplantation with HCV
}

\section{seropositive donors [version 1; peer review: 2 approved]}

\author{
Soumya Murag1, Brittany B. Dennis², Donghee Kim², Aijaz Ahmed², \\ George Cholankeril(102,3
}

${ }^{1}$ Department of Medicine, Santa Clara Valley Medical Center, Santa Clara, CA, USA

2Division of Gastroenterology and Hepatology, Stanford University School of Medicine, Stanford, CA, USA

${ }^{3}$ Department of Health Research and Policy, Division of Epidemiology, Stanford University School of Medicine, Stanford, CA, USA

V1 First published: 30 Dec 2019, 8(F1000 Faculty Rev):2151

https://doi.org/10.12688/f1000research.20387.1

Latest published: 30 Dec 2019, 8(F1000 Faculty Rev):2151

https://doi.org/10.12688/f1000research.20387.1

\section{Abstract}

The paradigm shift from interferon-based to direct-acting antiviral (DAA) therapy for the treatment of hepatitis $\mathrm{C}$ virus (HCV) infection has revolutionized the field of liver transplantation. These advances in effective HCV treatment, along with the persistent shortage in available liver grafts, have encouraged investigators to assess the need for adopting more inclusive donor policies. Owing to the poor outcomes following liver transplantation with recurrent HCV infection, liver transplantation using HCV seropositive donors (non-viremic and viremic) had been restricted. However, as a result of the growing supply of HCV seropositive donors from the recent opioid epidemic along with the advent of efficacious DAA therapy to treat HCV recurrence, there has been an increasing trend to use HCV seropositive donors for both HCV seropositive and seronegative recipients. The review aims to discuss recent advances and associated outcomes related to the use of HCV seropositive grafts for liver transplantation.

\section{Keywords}

HCV donor, liver transplantation, DAA therapy, hepatitis C virus

\section{Open Peer Review \\ Approval Status \\ 1 \\ 2 \\ version 1 \\ 30 Dec 2019 \\ Faculty Reviews are review articles written by the prestigious Members of Faculty Opinions. The articles are commissioned and peer reviewed before publication to ensure that the final, published version is comprehensive and accessible. The reviewers who approved the final version are listed with their names and affiliations.}

1. Marina C Berenguer, Hospital Universitario La Fe, University of Valencia-CIBEReHD,

Valencia, Spain

\section{Paul Martin, University of Miami Miller \\ School of Medicine, Miami, USA}

Any comments on the article can be found at the end of the article. 
Corresponding author: George Cholankeril (georgetc@stanford.edu)

Author roles: Murag S: Conceptualization, Data Curation, Formal Analysis, Methodology, Writing - Original Draft Preparation, Writing Review \& Editing; Dennis BB: Data Curation, Methodology, Resources, Writing - Original Draft Preparation, Writing - Review \& Editing; Kim D: Formal Analysis, Investigation, Methodology, Resources, Writing - Original Draft Preparation, Writing - Review \& Editing; Ahmed A: Conceptualization, Data Curation, Investigation, Methodology, Resources, Supervision, Validation, Writing - Original Draft Preparation, Writing - Review \& Editing; Cholankeril G: Conceptualization, Data Curation, Formal Analysis, Funding Acquisition, Investigation, Methodology, Project Administration, Resources, Software, Supervision, Validation, Visualization, Writing - Original Draft Preparation, Writing - Review \& Editing

Competing interests: AA has acted as an advisor for AbbVie, Gilead, and Intercept and has received research grants from Gilead and Intercept. The other authors declare that they have no competing interests.

Grant information: GC is supported by National Institutes of Health Training Grant T32DK007056. None of the other authors received financial or material support for the research and work in this manuscript.

The funders had no role in study design, data collection and analysis, decision to publish, or preparation of the manuscript.

Copyright: $\odot 2019$ Murag S et al. This is an open access article distributed under the terms of the Creative Commons Attribution License, which permits unrestricted use, distribution, and reproduction in any medium, provided the original work is properly cited.

How to cite this article: Murag S, Dennis BB, Kim D et al. Recent advances in liver transplantation with HCV seropositive donors [version 1; peer review: 2 approved] F1000Research 2019, 8(F1000 Faculty Rev):2151 https://doi.org/10.12688/f1000research.20387.1

First published: 30 Dec 2019, 8(F1000 Faculty Rev):2151 https://doi.org/10.12688/f1000research.20387.1 


\section{Introduction}

As the number of registrants awaiting liver transplantation (LT) far exceed the supply of available liver grafts ${ }^{1}$, there has been a greater focus on how to effectively use the available organs. Historically, donor liver grafts infected with hepatitis $\mathrm{C}$ virus (HCV) have been discarded or were used primarily in $\mathrm{HCV}$ seropositive recipients (viremic and non-viremic) because immediate and universal post-transplant $\mathrm{HCV}$ recurrence led to early allograft dysfunction in a significant proportion of recipients ${ }^{2,3}$. However, the advent of direct-acting antiviral (DAA) agents, especially with their favorable safety profile and efficacy, has greatly impacted the landscape for $\mathrm{LT}^{4}$. For over two decades, HCV was the most common indication for LT in the US. However, since the US Food and Drug Administration's approval of second-generation DAA agents in late 2013, the number of waitlist registrants and LT recipients with $\mathrm{HCV}$ has declined markedly. Despite the reduction in the waitlist burden related to $\mathrm{HCV}$, the number of total registrants awaiting LT continues to rise. In 2016, for the first time, both alcoholic liver disease and non-alcoholic steatohepatitis (NASH) had surpassed HCV as the leading indications of LT in the US ${ }^{5}$.

With early data demonstrating favorable outcomes with preemptive DAA treatment for HCV infection in the post-transplant setting, the use of $\mathrm{HCV}$ seropositive donor liver grafts has increased because of the growing shortage of available donor organs ${ }^{6}$. Moreover, in the setting of the recent opioid epidemic in the US, there is an increased prevalence of young, otherwise-healthy, $\mathrm{HCV}$-infected potential donors ${ }^{7,8}$. With the combination of the shortage of organs along with the changing landscape of HCV treatment with DAA agents and the opioid epidemic, it is an opportune time to expand the donor pool and improve overall outcomes for registrants awaiting LT. This review aims to assess the advances in the use of HCV seropositive donors which includes both $\mathrm{HCV}$ non-viremic (RNA-negative) and HCV viremic (RNA-positive) donor liver grafts in HCV seronegative recipients?.

\section{Current trends in the demand for liver grafts}

Amidst an ever-increasing shortage in donor organs, several policy changes have been implemented that prioritize medical urgency of LT rather than geography. For example, the search for a better allocation system led to the adoption and implementation of the Model for End-Stage Liver Disease (MELD) score which is composed of objective parameters that reflect medical acuity and necessity for LT. Over the past two decades, additional exception policies to the MELD score have been used to further prioritize medical urgency despite geographic location (Status 1A and Share 35 policies) as well as appropriately selecting and transplanting patients with hepatocellular carcinoma $^{10}$. This has led to a significant rise in the rate of LT surgeries performed, with a landmark 7841 LT surgeries in $2016^{1,10}$, the majority of which were from deceased donors. Moreover, deceased donor LT outcomes have improved; the incidence of post-transplant mortality and graft failure at 1 year decreased to under $10 \%$ for recipients.

Despite these advances, there continues to be an increasing annual number of waitlist registrants added to the LT list with a decreased number of candidates waiting at the end of the year, indicating rising rates of LT surgeries per year ${ }^{1}$. Projection models predict that the waitlist burden will continue to rise from the growing epidemic of NASH over the next two decades ${ }^{5}$, and current statistics suggest that $\mathrm{HCV}$ is no longer the most common indication for transplantation.

Owing to this persistent shortage of livers, attention has been given to expanding donor transplantation criteria to increase the available donor supply. Initially, this included using organs previously thought to be high-risk, such as those organs donated after cardiac death, from advanced donor age, and with minimal hepatic steatosis ${ }^{11,12}$. Living donor LT also had a great impact in expanding the donor pool and significantly shortened waiting times for recipients. Among these expanded criteria, the use of HCV seropositive liver grafts has increased because of the availability of effective therapies to treat HCV (DAA agents).

Currently, there are no consensus guidelines on the threshold of underlying degree of fibrosis in procured HCV-positive grafts compared with non-HCV grafts in the DAA era. The general acceptable cutoff is less than stage 3 fibrosis (F3) ${ }^{10}$. With pre-emptive DAA treatment in the peri-transplant setting, these concerns on fibrosis may be mitigated; however, further studies are needed to clarify this. Careful consideration should be taken when using HCV viremic or non-viremic liver grafts, including minimal steatosis $(<30 \%$ hepatocytes), necrosis $(<10 \%)$, and no more than mild non-specific portal inflammation on liver biopsy at the time of procurement ${ }^{10}$.

Prior to the availability of DAA agents and during the interferon era, HCV seropositive donors were three times more likely to be discarded than HCV seronegative donors or not considered for procurement at all. Currently, the overall proportion of livers discarded decreased from over $20 \%$ in 2010 to $9.0 \%$ in 2016; this was likely a reflection of the dramatic decrease in discard rates of HCV seropositive non-viremic donors. The dramatic reduction in discard rates can be explained in part by the mandated testing for HCV RNA and the ability to identify non-viremic donors. As of 2016, HCV seropositive non-viremic and HCV-negative donors had similar discard rates $(9.0 \%$ and $8.9 \%$, respectively), a result of the effective and well-tolerated DAA agents ${ }^{1,2}$.

The outcomes after transplantation with $\mathrm{HCV}$ seropositive viremic and non-viremic donors in both $\mathrm{HCV}$ seropositive and $\mathrm{HCV}$ seronegative recipients are discussed below.

\section{Natural progression of HCV in the post-transplant setting}

The discussion of antiviral therapy is important as it relates closely with the new trends in HCV donors in LT. HCV is a positive-stranded RNA virus, and testing of HCV includes serologic studies of anti-HCV antibody ( $\mathrm{HCV} \mathrm{Ab}$ ), which indicates exposure to the infection and may take 6 to 8 weeks to appear, and nucleic acid testing (NAT), which confirms active HCV infection and is detectable within 2 weeks of exposure. The eclipse period between viral exposure and positive NAT result is 
5 to 7 days, whereas the window period from exposure to positive antibody test is 60 to 70 days. This is particularly relevant in intravenous drug users who have the highest risk of negative test results in the eclipse period ${ }^{13}$, and repeat NAT testing should be considered in grafts that were NAT-negative at the time of procurement among all donors with increased risk for potential transmission.

Previously, HCV-positive donors referred to anyone with positive $\mathrm{HCV} \mathrm{Ab;} \mathrm{however,} \mathrm{this} \mathrm{is} \mathrm{incomplete} \mathrm{as} \mathrm{it} \mathrm{does} \mathrm{not} \mathrm{differentiate}$ between the presence and absence of viremia. Therefore, the new consensus suggests that any HCV-positive donor refers to those with positive NAT results ${ }^{13}$. The American Society of Transplantation Consensus Conference calls for a shift to replace the term "HCV-positive donor" with the term "HCV-viremic donor" ${ }^{13}$.

The natural progression of untreated HCV infection in LT recipients is well known ${ }^{14,15}$. Those with $\mathrm{HCV}$ viremia prior to transplant inevitably experience $\mathrm{HCV}$ recurrence post-transplant, resulting in graft dysfunction and progression to cirrhosis ${ }^{14}$.

Although DAA agents have been highly effective, little is known about the optimal time to provide HCV treatment of $\mathrm{HCV}$-infected recipients-before versus after transplantation. Treatment for renal transplant recipients is similar with two main strategies: treating $\mathrm{HCV}$-positive recipient either before or after transplantation. Treatment of HCV infection prior to kidney transplantation offered 0.43 more life-years than $\mathrm{HCV}$ treatment after transplantation; however, according to base-case analysis, transplantation of $\mathrm{HCV}$-infected kidney first with HCV treatment performed after transplantation was preferred for organ utilization and cost-effectiveness ${ }^{16}$. Similarly, a recent analysis has shown cost-effectiveness in treating HCV patients prior to transplantation if the risk of hepatic complications is modifiable with HCV treatment, reducing the cost burden from recurrent hospitalizations. However, treatment of $\mathrm{HCV}$ in those with advanced liver disease may not be cost-effective; while the MELD score may improve, ongoing poor health outcomes and repeated hospitalizations may not. After achieving viral clearance prior to transplantation, patients with $\mathrm{HCV}$ cannot receive livers from $\mathrm{HCV}$-positive donors, significantly limiting access to LT. In addition, recipients treated for $\mathrm{HCV}$ prior to transplantation would need to be retreated after transplantation if receiving a liver from an $\mathrm{HCV}$-positive donor, adding to the health-care cost. Therefore, the decision for HCV treatment prior to LT depends on the local and regional availability of HCV-positive donors. If there is a high proportion of HCVpositive donors, it may be beneficial to treat after transplantation.

Owing to the lack of large prospective data, there is no consensus on the timing of post-transplantation HCV treatment-early versus late treatment. Until 2011, HCV was treated primarily with a combination of pegylated interferon and ribavirin. However, their poor tolerance often led to necessary dose reductions or treatment discontinuations, along with sustained virologic response (SVR) of as low as $30.2 \%^{14}$. Therefore, interferon therapy was used primarily for treatment of $\mathrm{HCV}$ in liver recipients after transplant only if fibrosis was seen on biopsy ${ }^{15}$. However, with the advent of DAA agents, evidence favors treatment of $\mathrm{HCV}$ recurrence early in the post-transplant setting before the onset of fibrosis, leading to improved patient outcomes ${ }^{17}$. One study compared three DAA strategies: prior to transplantation, at the time of transplantation, and then at disease recurrence ${ }^{18}$. With the assumption of $96 \%$ probability of achieving SVR, DAA therapy remained the most cost-effective when used pre-transplantation in those with decompensated cirrhosis with a MELD score of less than 20. However, for a MELD score of more than 20 or for patients with $\mathrm{HCV}$, treatment at the time of recurrence is most effective when compared with treatment at the time of transplantation and pre-transplantation ${ }^{18}$.

\section{Treatment strategy in HCV recurrence post- transplantation}

Treatment data of those with HCV recurrence in an HCV seropositive recipient after transplantation differ from those who are HCV seronegative recipients. The latter will be highlighted later in the discussion as most data are in non-LT patients. The emergence of second- and third-generation DAA agents has resulted in SVR rates as high as $100 \%$ when used during LT $^{19-21}$. Several studies have attempted to demonstrate the efficacy of various treatment regiments for different genotypes of $\mathrm{HCV}$.

In 2016, the American Association for the Study of Liver Disease (AASLD) and the Infectious Disease Society of America (IDSA) co-jointly published treatment guidelines for the recurrence of $\mathrm{HCV}$ infection after transplantation. Patients with chronic HCV received 12 weeks of sofosbuvir/velpatasvir after recurrence of $\mathrm{HCV}$ after transplantation and showed a 3-month follow-up of $96 \%$ cure $^{22}$. In patients with HCV genotype 2 or 3 infection, non-ribavirin-based formulations include a 12-week daily course of glecaprevir/pibrentasvir or sofosbuvir/velpatasvir for LT recipients with or without compensated cirrhosis ${ }^{23}$. Its pangenotypic treatment profile and efficacy have favorable SVR in smaller single- and multi-center studies as well.

Several landmark DAA clinical trials for the treatment of HCV are outlined below. The SOLAR-1 trial in 2015 demonstrates that sofosbuvir, ledipasvir, and ribavirin for 12 to 24 weeks achieved an SVR of 96 to $98 \%$ for HCV genotype 1 and 4 in transplant recipients without cirrhosis, and SVR was lower for patients with decompensated cirrhosis ${ }^{24}$. ASTRAL-1 tested for all genotypes except genotype 3, finding an overall SVR rate of 99\% when using a sofosbuvir and velpatasvir combination treatment for 12 weeks ${ }^{25}$; ASTRAL-3 looked particularly at genotype 3, which showed superior SVR than standard treatment (sofosbuvir and ribavirin). Multiple trials have evaluated daclatasavir and sofosbuvir with or without ribavirin for 12 weeks in LT recipients with advanced cirrhosis with a 91 to 95\% SVR among different genotypes ${ }^{26}$. Special populations such as severe chronic kidney disease (stage IV) or end-stage renal disease are important to highlight. Particularly, sofosbuvirbased regimens have been safe and effective in those with stage IV or $\mathrm{V}$ chronic kidney disease. The combination of elbasvir and grazoprevir has been recommended for genotypes 1 and 4 for 12 weeks, and glecaprevir and pibrentasvir for all genotypes for 8 to 16 weeks ${ }^{27}$. 


\section{Outcomes of HCV non-viremic and viremic donor liver grafts into HCV-positive recipients}

As of 2017, $16.9 \%$ of HCV seropositive LT recipients received liver grafts from $\mathrm{HCV}$ viremic and non-viremic donors ${ }^{2}$. The majority of initial studies were conducted before the DAA era, and reported results are for HCV "positive" donors without any delineation regarding viremia. Initially, using HCV seropositive donors for immunocompromised recipients created anticipation. Since 1992, the majority of the studies showed no difference between HCV seropositive grafts and $\mathrm{HCV}$ seronegative grafts in HCV seropositive recipients ${ }^{28}$. However, these outcomes did not measure long-term outcomes and lacked histological data such as fibrosis, which would give more compelling evidence. A cohort study among five different US transplant centers from 2002 through 2007 showed that transplantation with $\mathrm{HCV}$ seropositive grafts was associated with a $58 \%$ increased risk of advanced fibrosis ${ }^{12}$.

One study assessed the recipients of $32 \mathrm{HCV}$ seropositive donor liver grafts, of whom 15 had HCV viremia ${ }^{29}$. These data demonstrated no significant difference in patient or graft survival for $\mathrm{HCV}$ seropositive recipients who received an $\mathrm{HCV}$ seropositive liver graft regardless of viremia status. Similarly, a matched case-control analysis in the European registry showed no difference in patient and graft survival when the three groups of $\mathrm{HCV}$ seronegative, $\mathrm{HCV}$ viremic, and $\mathrm{HCV}$ non-viremic grafts were compared. Among the $\mathrm{HCV}$ seropositive group, viremic donors predispose recipients to recurrent HCV infection and subsequent development of fibrosis after transplantation more than non-viremic donors. It was also evident that there is a higher prevalence of fibrosis in the group of $\mathrm{HCV}$ viremic donors than $\mathrm{HCV}$ non-viremic donors, leading to the question of whether $\mathrm{HCV}$ viremia status is a confounding factor in the analysis ${ }^{30}$. Owing to the risk of advanced fibrosis, the main risk factor for early hepatitis $\mathrm{C}$ recurrence, most studies recommend wary use of $\mathrm{HCV}$ RNA-positive donors in $\mathrm{HCV}$ seropositive patients.

\section{Outcomes of HCV non-viremic and viremic liver grafts into HCV seronegative recipients}

The safety and efficacy of DAA therapy in HCV-infected recipients have resulted in consideration of transplantation of $\mathrm{HCV}$ seropositive grafts in $\mathrm{HCV}$ seronegative recipients followed by early post-transplant treatment. Data regarding the use of $\mathrm{HCV}$ seropositive donors in $\mathrm{HCV}$ seronegative recipients are limited. Whereas discard rates of HCV non-viremic livers have decreased, discard rates of livers from HCV viremic donors continue to remain higher than $30 \%^{31}$. Post-transplant viremia is evident even with donors who are found to be $\mathrm{HCV}$ non-viremic at the time of procurement. A recent report of $26 \mathrm{HCV}$ non-viremic donor liver grafts transplanted into $\mathrm{HCV}$ seronegative recipients was studied, and 3-month post-transplant follow-up revealed that $\mathrm{HCV}$ transmission, which was confirmed by HCV NAT, occurred in four (16\%) out of 26 recipients $^{32}$. This study was conducted in donors who met highrisk criteria for infectious transmission and may fall in the eclipse period where viremia was not accurately detected by NAT assay. Cotter et al. collected data from the Scientific Registry of
Transplant Recipients for all recipients who underwent LT from January 2008 through January 2018. Graft survival at 1 and 2 years following LT from $\mathrm{HCV}$ viremic donors was similar to that of $\mathrm{HCV}$ non-viremic donors ${ }^{9}$. A recent systematic review of 15 studies with HCV-positive donors assesses for patient and graft survival in $\mathrm{HCV}$-negative recipients ${ }^{33}$. Six of these studies were from national LT registries from both the US and multicenter European databases (sample sizes ranged from 38 to 1930 patients) and showed no difference in graft or patient survival. Overall, the HCV serostatus of recipient, not of the donor graft, was an independent predictor of graft survival ${ }^{12,29}$.

A Markov modeling study conducted in the US by Chhatwal et al. showed that $\mathrm{HCV}$ seronegative patients have an increased life expectancy by accepting any liver graft, regardless of $\mathrm{HCV}$ status if the MELD score was greater than or equal to $20^{34}$. Candidates in United Network for Organ Sharing (UNOS) regions with longer waitlist time to transplant may also benefit from accepting HCV seropositive donors. In HCV seropositive donors who had previously achieved SVR, using HCV viremic grafts may be associated with lower SVR and additional treatment costs but has still shown to be cost-effective in patients awaiting LT particularly with MELD scores above $23^{35}$.

Recent studies have evaluated national trends on the use of $\mathrm{HCV}$ seropositive donors into $\mathrm{HCV}$ seronegative recipients, stratified by donor viremia ${ }^{31,36}$. In total, $355 \mathrm{HCV}$ seropositive liver grafts have been transplanted into $\mathrm{HCV}$ seronegative recipients from April 2015 to December 2018 in the US. Since 2017, there was an increase in LT from HCV non-viremic liver grafts to $\mathrm{HCV}$ seronegative recipients ranging from 1 to 8 per month and LT from HCV viremic donors to HCV seronegative recipients from 1 to 12 per month.

Transplantation of $\mathrm{HCV}$ viremic livers into $\mathrm{HCV}$ seronegative patients with prophylactic DAA agents could improve patient survival, and benefits may outweigh the harm of introducing a viral infection, particularly among those in need of immediate transplantation. Few trials have studied the efficacy of DAA agents for LT from $\mathrm{HCV}$ viremic donors to unexposed recipients, and most trials have been conducted in non-LTs. In a single-center non-randomized trial, non-HCVinfected recipients were treated prophylactically with grazoprevir and elbasvir immediately before and after transplantation from $\mathrm{HCV}$ viremic donors, and no HCV RNA was detected in recipients 12 weeks after prophylactic treatment before or after renal transplantation ${ }^{37}$. It is difficult to conclude whether this provides true prophylaxis or early treatment of $\mathrm{HCV}$ infection.

A single institution study was conducted on adult HCV seropositive recipients who contracted $\mathrm{HCV}$ viremia after transplantation from $\mathrm{HCV}$ viremic donors. All patients began DAA therapy (sofosbuvir/velpatasvir/ribavarin combination) within 3 months of transplant and achieved SVR with no development of complications such as graft failure, fibrosing cholestatic hepatitis, or death ${ }^{38}$. DAA therapy may interact with immunosuppressive drugs as the rate of biopsy-proven rejection was higher than 
the average rate seen in rejection of general LT. In fact, HCV treatment post-transplant has been associated with rejection and immune graft dysfunction.

\section{Conclusions}

The recent opioid epidemic has resulted in a rising number of deaths among young, otherwise-healthy adults with HCV infection, contributing to the surge in available and used $\mathrm{HCV}$ viremic donors with favorable donor criteria. In addition, the era of DAA agents has seen a surge in the use of HCV-infected non-viremic and viremic donors in $\mathrm{HCV}$-unexposed patients with early favorable outcomes. Overall, the outcome of $\mathrm{HCV}$ seropositive recipients who receive $\mathrm{HCV}$ viremic organs is limited with only a few liver, kidney, and heart transplants studied thus far.

The inequity in access to LT across the country contributes to the high waitlist death rate. Several questions remain regarding the accessibility to $\mathrm{HCV}$ treatment, and long-term outcomes need to be addressed in the near future.

\section{Abbreviations}

DAA, direct-acting antiviral; $\mathrm{HCV}$, hepatitis $\mathrm{C}$ virus; LT, liver transplantation; MELD, Model for End-Stage Liver Disease; NASH, nonalcoholic steatohepatitis; NAT, nucleic acid testing; SVR, sustained virologic response
1. Kim WR, Lake JR, Smith JM, et al.: OPTN/SRTR 2016 Annual Data Report: Liver Am J Transplant. 2018; 18 Suppl 1: 172-253. PubMed Abstract | Publisher Full Text

2. F Bowring MG, Kucirka LM, Massie AB, et al: Changes in Utilization and Discard of Hepatitis C-Infected Donor Livers in the Recent Era. Am J Transplant. 2017; 17(2): 519-27.

PubMed Abstract | Publisher Full Text | Free Full Text | F1000 Recommendation

3. Northup PG, Argo CK, Nguyen DT, et al.: Liver allografts from hepatitis C positive donors can offer good outcomes in hepatitis $C$ positive recipients: A US National Transplant Registry analysis. Transpl Int. 2010; 23(10): 1038-44. PubMed Abstract | Publisher Full Text

4. F Kwo PY, Mantry PS, Coakley E, et al:: An Interferon-free Antiviral Regimen for HCV after Liver Transplantation. N Engl J Med. 2014; 371(25): 2375-82. PubMed Abstract | Publisher Full Text | F1000 Recommendation

5. Cholankeril G, Ahmed A: Alcoholic Liver Disease Replaces Hepatitis C Virus Infection as the Leading Indication for Liver Transplantation in the United States. Clin Gastroenterol Hepatol. 2018; 16(8): 1356-8. PubMed Abstract | Publisher Full Text | Free Full Text

6. Cholankeril G, Li AA, March KL, et al.: Improved Outcomes in HCV Patients Following Liver Transplantation During the Era of Direct-Acting Antiviral Agents. Clin Gastroenterol Hepatol. 2018; 16(3): 452-3. PubMed Abstract | Publisher Full Text

7. F Gonzalez SA, Trotter JF: The rise of the opioid epidemic and hepatitis C-positive organs: A new era in liver transplantation. Hepatology. 2018; 67(4): 1600-8.

PubMed Abstract | Publisher Full Text | F1000 Recommendation

8. U.S. 2016 Surveillance Data for Viral Hepatitis. (2018, April 16); Retrieved November 21, 2019. Reference Source

9. $\mathrm{F}$ Cotter TG, Paul S, Sandıkçı B, et al.: Increasing Utilization and Excellent Initial Outcomes Following Liver Transplant of Hepatitis C Virus (HCV)-Viremic Donors Into HCV-Negative Recipients: Outcomes Following Liver Transplant of HCV-Viremic Donors. Hepatology. 2019; 69(6): 2381-95.

PubMed Abstract | Publisher Full Text | F1000 Recommendation

10. Starzl TE: History of Liver and Other Splanchnic Organ Transplantation. In: Doria C. (eds) Contemporary Liver Transplantation. Organ and Tissue Transplantation. Springer, Cham, 2017; 1-28. Publisher Full Text

11. deLemos AS, Vagefi PA: Expanding the donor pool in liver transplantation: Extended criteria donors. Clin Liver Dis (Hoboken). 2013; 2(4): 156-159. PubMed Abstract | Publisher Full Text | Free Full Text

12. Lai JC, O'Leary JG, Trotter JF, et al.: Risk of advanced fibrosis with grafts from hepatitis $\mathbf{C}$ antibody-positive donors: A multicenter cohort study. Liver Transpl. 2012; 18(5): 532-8

PubMed Abstract | Publisher Full Text | Free Full Text

13. Levitsky J, Formica RN, Bloom RD, et al:: The American Society of Transplantation Consensus Conference on the Use of Hepatitis C Viremic Donors in Solid Organ Transplantation. Am J Transplant. 2017; 17(11): 2790-802. PubMed Abstract | Publisher Full Text

14. Berenguer M: Systematic review of the treatment of established recurrent hepatitis $\mathbf{C}$ with pegylated interferon in combination with ribavirin. $J$ Hepatol.
2008; 49(2): 274-87.

PubMed Abstract | Publisher Full Text

15. F Little EC, Berenguer M: The New Era of Hepatitis C: Therapy in Liver Transplant Recipients. Clin Liver Dis. 2017; 21(2): 421-34. PubMed Abstract | Publisher Full Text | F1000 Recommendation

16. F Latt NL: Update on the Management of Hepatitis C Virus Infection in the Setting of Chronic Kidney Disease and Kidney Transplantation. Gastroenterol Hepatol (N Y). 2018; 14(12): 687-705.

PubMed Abstract | Free Full Text | F1000 Recommendation

17. Gadiparthi C, Cholankeril G, Perumpail BJ, et al.: Use of direct-acting antiviral agents in hepatitis $C$ virus-infected liver transplant candidates. World $J$ Gastroenterol. 2018; 24(3): 315-22. PubMed Abstract | Publisher Full Text | Free Full Text

18. F Cortesi PA, Belli LS, Facchetti R, et al:: The optimal timing of hepatitis C therapy in liver transplant-eligible patients: Cost-effectiveness analysis of new opportunities. J Viral Hepat. 2018; 25(7): 791-801.

PubMed Abstract | Publisher Full Text | F1000 Recommendation

19. F Burton MJ: In DAA We Trust: Key Factors Essential to HCV Elimination. Dig Dis Sci. 2019; 64(10): 2701-2.

PubMed Abstract | Publisher Full Text | F1000 Recommendation

20. F Jacobson IM, Lawitz E, Gane EJ, et al.: Efficacy of $\mathbf{8}$ Weeks of Sofosbuvir, Velpatasvir, and Voxilaprevir in Patients With Chronic HCV Infection: 2 Phase 3 Randomized Trials. Gastroenterology. 2017; 153(1): 113-22. PubMed Abstract | Publisher Full Text | F1000 Recommendation

21. F Campos-Varela I, Agudelo EZ, Sarkar M, et al.: Use of a hepatitis C virus (HCV) RNA-positive donor in a treated HCV RNA-negative liver transplant recipient. Transpl Infect Dis. 2018; 20(1): e12809. PubMed Abstract | Publisher Full Text | Free Full Text | F1000 Recommendation

22. F Agarwal K, Castells L, Müllhaupt B, et al.: Sofosbuvir/velpatasvir for 12-weeks in genotype 1-4 HCV-infected liver transplant recipients. Journal of Hepatology. 2018; 69(3): 603-7.

PubMed Abstract | Publisher Full Text | F1000 Recommendation

23. F Reau N, Kwo PY, Rhee S, et al:: Glecaprevir/Pibrentasvir Treatment in Liver or Kidney Transplant Patients With Hepatitis C Virus Infection. Hepatology. 2018; 68(4): 1298-307.

PubMed Abstract | Publisher Full Text | Free Full Text | F1000 Recommendation

24. F Charlton M, Everson GT, Flamm SL, et al.: Ledipasvir and Sofosbuvir Plus Ribavirin for Treatment of HCV Infection in Patients With Advanced Liver Disease. Gastroenterology. 2015; 149(3): 649-59. PubMed Abstract | Publisher Full Text | F1000 Recommendation

25. F Feld JJ, Jacobson IM, Hézode C, et al:: Sofosbuvir and Velpatasvir for HCV Genotype 1, 2, 4, 5, and 6 Infection. N Engl J Med. 2015; 373(27): 2599-607. PubMed Abstract | Publisher Full Text | F1000 Recommendation

26. F Kwo P, Fried MW, Reddy KR, et al.: Daclatasvir and sofosbuvir treatment of decompensated liver disease or post-liver transplant hepatitis $C$ virus recurrence in patients with advanced liver disease/cirrhosis in a real-world cohort. Hepatol Commun. 2018; 2(4): 354-63.

PubMed Abstract | Publisher Full Text | Free Full Text | F1000 Recommendation

27. HCV Guidance: Recommendations for Testing, Managing, and Treating 
Hepatitis C. 2018; Retrieved November 21, 2019 Reference Source

28. Vargas HE, Laskus T, Wang LF, et al:: Outcome of liver transplantation in hepatitis $C$ virus-infected patients who received hepatitis $C$ virus-infected grafts. Gastroenterology. 1999; 117(1): 149-53. PubMed Abstract | Publisher Full Text

29. O'Leary JG, Neri MA, Trotter JF, et al:: Utilization of hepatitis $\mathbf{C}$ antibody-positive livers: genotype dominance is virally determined. Transpl Int. 2012; 25(8): 825-9.

PubMed Abstract | Publisher Full Text | Free Full Text

30. Ballarin R, Cucchetti A, Spaggiari M, et al.: Long-term follow-up and outcome of liver transplantation from anti-hepatitis $\mathbf{C}$ virus-positive donors: a European multicentric case-control study. Transplantation. 2011; 91(11): 1265-72. PubMed Abstract | Publisher Full Text

31. Cholankeril G, Li AA, Dennis BB, et al:: Increasing Trends in Transplantation of HCV-Positive Livers Into Uninfected Recipients. Clin Gastroenterol Hepatol. 2019; 17(8): 1634-6.

PubMed Abstract | Publisher Full Text | Free Full Text

32. F Bari K, Luckett K, Kaiser $\mathrm{T}$, et al:: Hepatitis $\mathrm{C}$ transmission from seropositive, nonviremic donors to non-hepatitis $\mathrm{C}$ liver transplant recipients. Hepatology. 2018; 67(5): 1673-82. PubMed Abstract | Publisher Full Text | F1000 Recommendation

33. F Shetty A, Buch A, Saab S: Use of Hepatitis C-Positive Liver Grafts in
Hepatitis C-Negative Recipients. Dig Dis Sci. 2019; 64(5): 1110-8. PubMed Abstract | Publisher Full Text | F1000 Recommendation

34. $\mathrm{F}$ Chhatwal J, Samur S, Bethea ED, et al:: Transplanting hepatitis $\mathrm{C}$ viruspositive livers into hepatitis $C$ virus-negative patients with preemptive antivira treatment: A modeling study. Hepatology. 2018; 67(6): 2085-95.

PubMed Abstract | Publisher Full Text | Free Full Text | F1000 Recommendation

35. F Saab S, Kardashian A, Saggi S, et al.: Use of hepatitis C-positive grafts in hepatitis C-negative liver transplant recipients is cost effective. Clin Transplant. 2018; 32(10): e13383.

PubMed Abstract | Publisher Full Text | F1000 Recommendation

36. $F$ Bowring MG, Shaffer AA, Massie AB, et al:: Center-level trends in utilization of HCV-exposed donors for HCV-uninfected kidney and liver transplan recipients in the United States. Am J Transplant. 2019; 19(8): 2329-41. PubMed Abstract | Publisher Full Text | Free Full Text | F1000 Recommendation

37. F Durand CM, Bowring MG, Brown DM, et al.: Direct-Acting Antiviral Prophylaxis in Kidney Transplantation From Hepatitis C Virus-Infected Donors to Noninfected Recipients: An Open-Label Nonrandomized Trial. Ann Intern Med. 2018; 168(8): 533-540.

PubMed Abstract | Publisher Full Text | Free Full Text | F1000 Recommendation

38. Kwong AJ, Wall A, Melcher M, et al:: Liver transplantation for hepatitis $\mathrm{C}$ virus (HCV) non-viremic recipients with HCV viremic donors. Am J Transplant. 2019; 19(5): 1380-7.

PubMed Abstract | Publisher Full Text | Free Full Text 


\section{Open Peer Review}

\section{Current Peer Review Status:}

\section{Editorial Note on the Review Process}

Faculty Reviews are review articles written by the prestigious Members of Faculty Opinions. The articles are commissioned and peer reviewed before publication to ensure that the final, published version is comprehensive and accessible. The reviewers who approved the final version are listed with their names and affiliations.

\section{The reviewers who approved this article are:}

\section{Version 1}

\section{Paul Martin}

Department of Medicine, Division of GI/Hepatology, University of Miami Miller School of Medicine, Miami, FL, USA

Competing Interests: No competing interests were disclosed.

\section{Marina C Berenguer}

Liver Transplantation \& Hepatology Unit, Hospital Universitario La Fe, University of Valencia-

CIBEReHD, Valencia, Spain

Competing Interests: No competing interests were disclosed.

The benefits of publishing with F1000Research:

- Your article is published within days, with no editorial bias

- You can publish traditional articles, null/negative results, case reports, data notes and more

- The peer review process is transparent and collaborative

- Your article is indexed in PubMed after passing peer review

- Dedicated customer support at every stage

For pre-submission enquiries, contact research@f1000.com 